\title{
Association between the Interleukin-10 -1082 G/A polymorphism and risk of hepatocellular carcinoma
}

\author{
Yingwei Wang ${ }^{1}$, Peiyang $\mathrm{Hu}^{2}$
}

1. Clinical laboratory, Tiantai people’s hospital, Tiantai, Zhejiang 317200, China;

2. Department of traumatology,Tiantai people's hospital, Tiantai, Zhejiang 317200, China.

\begin{abstract}
Background: Inconsistent results have been reported from studies investigating the relationship of the interleukin-10 (IL-10) $-1082 \mathrm{G} / \mathrm{A}$ polymorphism and the susceptibility of hepatocellular carcinoma (HCC). Therefore, a thorough literature review of relatedstudies was performed in this meta-analysis to examine the association of the interleukin-10(IL-10) -1082 G/A polymorphism with HCC susceptibility.

Methods: Electronic databases were searched for literature on the relationship between interleukin-10(IL-10) -1082 G/A polymorphism and the risk of HCC in accordance with the inclusion and exclusion criteria. The selected studies were analyzed using the Stata 12.0 software. Finally, the strength of the associations was evaluated using the odds ratio (OR) and $95 \%$ confidence intervals $(95 \% \mathrm{CI})$.

Results: A total of six case-control studies were enrolled into the current meta-analysis, which included a total of 911 patients and 1889 control subjects. Our data revealed no association between the IL-10 -1082 G/A polymorphism and the risk of HCC (GG vs AA:OR=0.84, 95\%CI=0.57-1.25; AG vs AA:OR=0.85, 95\% CI =0.70-1.05; Dominant model: $\mathrm{OR}=0.85,95 \% \mathrm{CI}=0.70$ 1.03; and Recessive model: $\mathrm{OR}=0.92,95 \% \mathrm{CI}=0.64-1.32)$. Similarly, no association was found in sub-group analysis based on ethnicity.
\end{abstract}

Conclusion: The results of our study suggest no association between IL-10 -1082 G/A polymorphism and the risk of HCC. Keywords: Hepatocellular carcinoma, IL-10 polymorphism, risk analysis.

DOI: https://dx.doi.org/10.4314/ahs.v20i1.40

Cite as: Wang Y, Hu P. Association between the Interleukin-10 -1082 G/A polymorphism and risk of hepatocellular carcinoma. Afri Health Sci. 2020;20(1):351-8. bttps://dx.doi.org/10.4314/abs.v20i1.40

\section{Introduction}

As a global health problem, hepatocellular carcinoma (HCC) presents a tremendous economic burden on both patients and society. HCC is the fifth most commonly diagnosed cancer, and is the second-highest cause of cancer-related deaths worldwide ${ }^{1}$. China has an average of about 695,000 primary liver cancer-induced deaths annually, accounting for $45 \%$ of the mortality worldwide. Typically, early detection of HCC is of crucial significance, since more advanced HCC cases typically are associated with poor prognosis. HCC is mainly caused by infection

$$
\begin{aligned}
& \text { Corresponding author: } \\
& \text { Peiyang Hu, } \\
& \text { Department of traumatology, } \\
& \text { Tiantai people's hospital, Tiantai, Zhejiang } \\
& \text { 317200, China; } \\
& \text { Phone:+860576 83987166. } \\
& \text { Email: hu_peiyang@126.com }
\end{aligned}
$$

with chronic hepatitis $B$ virus and hepatitis $C$ virus $^{2}$. There are other well-recognized risk factors, such as smoking, drinking, and exposure to aflatoxin ${ }^{3}$. Furthermore, recent studies examining genetic changes during HCC genesis and development suggest potential genetic factors that can also contribute to the development of cancer ${ }^{4}$. Specifically, single nucleotide polymorphism (SNP) changes are extensively investigated genetic variations that may contribute to the risk of disease development.

Recent studies have shown that cytokines including transforming growth factor, interleukin-6 (IL-6), IL-8, and IL-10, play critical roles in cancer etiologies- ${ }^{8}$. Of these factors, IL-10 is an anti-inflammatory cytokine, which shows immune suppression'. An increasing amount of evidence indicates that IL-10 may inhibit carcinogenesis, angiogenesis, and tumor metastasis ${ }^{10}$. In contrast, a deficiency in IL-10 will promote pro-inflammatory cytokines production, restrain anti-cancer immunity, and facilitate tumor growth ${ }^{11}$. 
The human IL-10 gene, which is located on chromosome 1 (1q31-q32), encodes an acid-sensitive homodimeric protein encoded by five exons and four introns. There are several SNPs in the promoter region of the IL-10 gene, including -1082 G/A, -819 T/C, and -592 A/C, which can alter the transcription start site to influence IL-10 mRNA transcription ${ }^{12}$. Polymorphism in the promoter region of the IL-10 gene may be correlated with changes in IL-10 expression, which may thereby give affect tumorigenesis $^{13}$.

The association of the IL-10 -1082 G/A(NCBI ID:rs1800896) polymorphism with the risk of incidence of HCC was recently examined, but the findings have been inconsistent. A single study with a relatively small sample size may not be sufficient to detect a very small effect of the polymorphism on HCC. For this reason, the current meta-analysis was conducted to comprehensively assess the association of the IL-10 -1082 G/A polymorphism with HCC susceptibility.

\section{Methods}

\section{Literature Search}

We searched for relevant studies in the PubMed and CNKI electronic databases using the terms "liver cancer" or "hepatocellular carcinoma" "interleukin-10" or "IL10 " and "polymorphism". Studies published by the same authors were checked for overlapping participant groups. In the case of partially overlapping studies, the most recent article was used.

\section{Inclusion and exclusion criteria}

For inclusion in this meta-analysis, the studies must have met the following criteria: 1) a case-control design including HCC cases and healthy controls; 2) reporting the association between the $-1082 \mathrm{G} / \mathrm{A}$ polymorphism and susceptibility to HCC; and 3) the inclusion of sufficient genotype data for extraction. The exclusion criteria were: 1) non-case-control studies evaluating the association between the $-1082 \mathrm{G} / \mathrm{A}$ polymorphism and HCC risk; 2) case reports, letters, reviews, and editorial articles; and 3) studies with incomplete raw data or without usable data reported.

\section{Quality score assessment}

The quality of the included studies was assessed based on a set of predetermined criteria (Table 1), and include the representativeness of cases, source of controls, certainty of HCC diagnosis, total sample size, quality control of genotyping methods, and evidence of Hardy-Weinberg equilibrium (HWE) in the control population. Different opinions were resolved by discussion to reach consensus14. Papers scoring $<10$ were classified as "low quality" and those scoring $\geq 10$ were classified as "high quality." 
Table 1. Scale for quality assessment

\begin{tabular}{|c|c|}
\hline Criteria & Score \\
\hline \multicolumn{2}{|l|}{ Source of cases } \\
\hline $\begin{array}{l}\text { Selected from population } \\
\text { registry or }\end{array}$ & $\begin{array}{l}3 \\
2 \\
1 \\
0\end{array}$ \\
\hline \multicolumn{2}{|l|}{ Source of controls } \\
\hline $\begin{array}{l}\text { Population-based } \\
\text { Blood donors or volunteers } \\
\text { Hospital-based (cancer-free patients) } \\
\text { Not described }\end{array}$ & $\begin{array}{l}3 \\
2 \\
1 \\
0\end{array}$ \\
\hline \multicolumn{2}{|l|}{ Specimens obtained from patients to determine genotypes } \\
\hline $\begin{array}{l}\text { White blood cells or normal tissues } \\
\text { Tumor tissues or exfoliated cells of tissue }\end{array}$ & $\begin{array}{l}3 \\
0\end{array}$ \\
\hline \multicolumn{2}{|l|}{ Hardy-Weinberg equilibrium in controls } \\
\hline $\begin{array}{l}\text { Hardy-Weinberg equilibrium } \\
\text { Hardy-Weinberg disequilibrium }\end{array}$ & $\begin{array}{l}3 \\
0\end{array}$ \\
\hline \multicolumn{2}{|l|}{ Totalsample size } \\
\hline $\begin{array}{l}\geq 1000 \\
\geq 500 \text { but }<1000 \\
\geq 200 \text { but }<500 \\
>0 \text { but }<200\end{array}$ & $\begin{array}{l}3 \\
2 \\
1 \\
0\end{array}$ \\
\hline
\end{tabular}

\section{Data extraction}

Information was independently extracted carefully from all eligible publications by two authors, based on the inclusion criteria above. Disagreements were resolved by discussion between the two authors. The following data were collected from each article: first author, publication date, country where study was performed, number of cases and controls, genotype frequencies of case and control groups, quality score, and evidence of HWE in the control group.

\section{Statistical analysis}

Statistical analysis was performed using the Stata software package, version 12.0 (StataCorp LP, College Station, TX, USA), and P-values less than 0.05 were considered statistically significant. The association between the IL-10 -1082 G/A polymorphism and HCC risk were estimated by pooled ORs with 95\% CI for homozygote comparison (GG vs. AA), heterozygote comparison (AG vs. AA), dominant model ( $G G+A G$ vs. $A A)$ and the recessive model (GG vs. AG+ AA). Heterogeneity was investigated and measured using the I2 statistic, where I $2>50 \%$ indicated evidence of heterogeneity. When heterogeneity was present, the random effects model was used to calculate the pooled OR, otherwise the fixed effects model was used. One-way sensitivity analyses were performed to determine the stability of the results, where each individual study in the meta-analysis was individually omitted to reflect the influence of each individual dataset on the pooled $\mathrm{OR}^{15}$. Publication bias was evaluated using the funnel plot with Egger's test. Power analysis was performed using the statistical program PS: Power and Sample Size Calculation (http://biostat.mc.vanderbilt.edu/ wiki/Main/PowerSampleSize). 


\section{Results}

\section{Study characteristics}

A flow diagram of the study selection process is shown in Figure 1. A total of 181 potentially relevant studies were identified from the database searches. Of these, 170 studies were excluded based on the title or abstract. In addition, one study was excluded because the full text was not available, two were excluded because they were not case-control studies, and two were excluded because they lacked the necessary data. After exclusion, six studies remained and were included in this meta-analysis ${ }^{16-21}$.
The characteristics of the included studies are presented in Table 2. There were four studies conducted in Asian populations, and two in mixed populations. Together, the studies included a total of 911 cases and 1889 controls. The genotype distributions in the control groups in all studies were consistent with HWE. All publications were written in English. All included studies were of high quality, with quality score assessments higher than or equal to 10 points. The statistical powers of included studies ranged from $52.6 \%$ to $72.3 \%$. None of the studies had a statistical power exceeding $80 \%$.

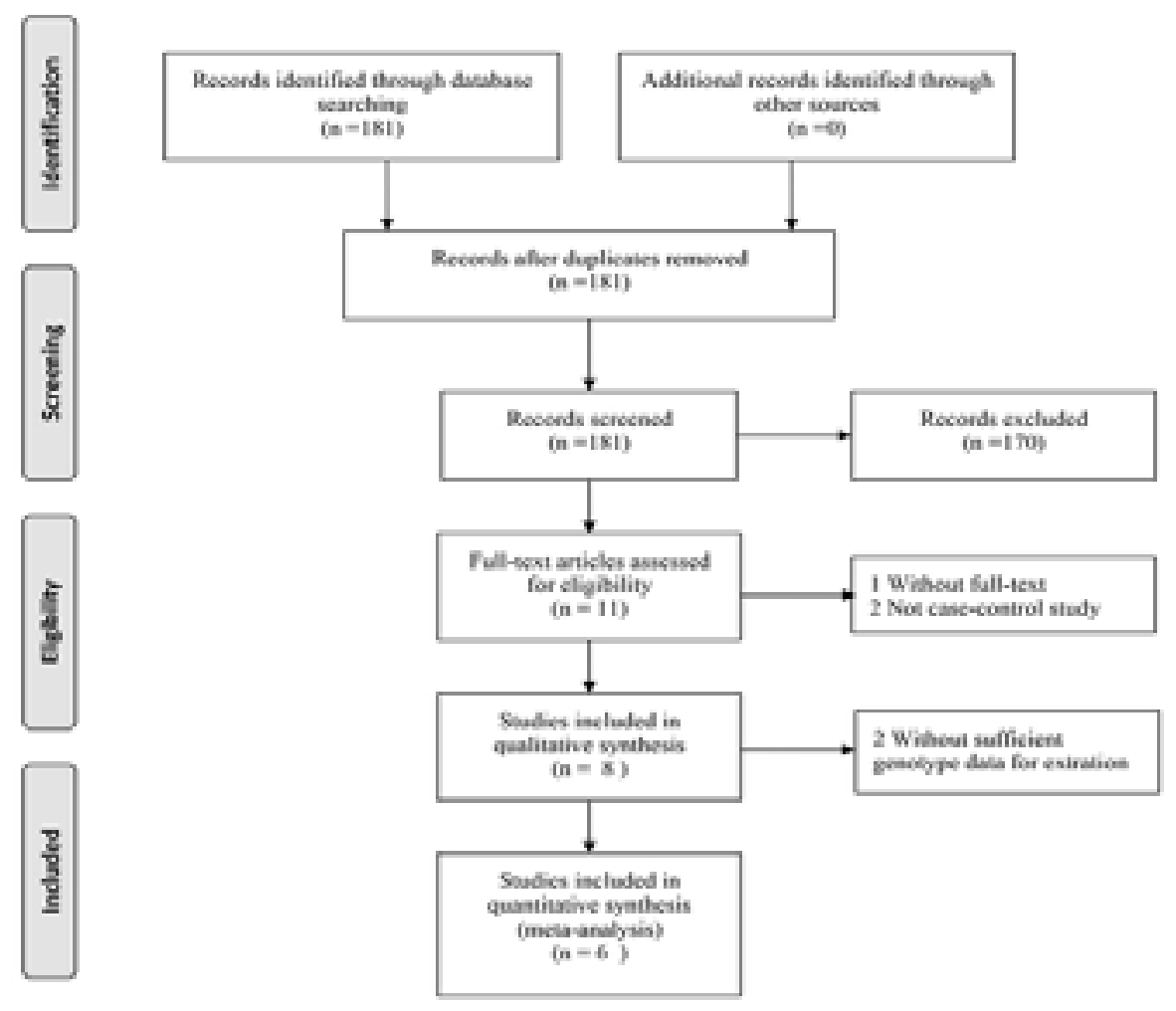

Figure 1. Study selection and inclusion process

Table 2. Characteristics of studies included in the meta-analysis

\begin{tabular}{|c|c|c|c|c|c|c|c|c|c|c|}
\hline \multirow[t]{2}{*}{$\begin{array}{l}\text { Study } \\
\text { included }\end{array}$} & \multirow[t]{2}{*}{ Area } & \multirow[t]{2}{*}{$\begin{array}{l}\text { Cases/ } \\
\text { Controls }\end{array}$} & \multicolumn{3}{|c|}{$\begin{array}{l}\text { Genotypes for } \\
\text { cases }\end{array}$} & \multicolumn{3}{|c|}{$\begin{array}{l}\text { Genotypes for } \\
\text { controls }\end{array}$} & \multirow[t]{2}{*}{$\begin{array}{l}\text { HWE } \\
\text { test }\end{array}$} & \multirow[t]{2}{*}{$\begin{array}{l}\text { Quality } \\
\text { scores }\end{array}$} \\
\hline & & & AA & $\mathrm{AG}$ & GG & AA & $A G$ & GG & & \\
\hline Shin 2003 & Korea & $230 / 792$ & 201 & 28 & 1 & 675 & 112 & 5 & 0.88 & 12 \\
\hline $\begin{array}{l}\text { Heneghan } \\
2003\end{array}$ & China & $98 / 175$ & 86 & 12 & 0 & 160 & 15 & 0 & 0.55 & 10 \\
\hline $\begin{array}{l}\text { Nieters } \\
2005\end{array}$ & China & $249 / 250$ & 130 & 99 & 20 & 115 & 109 & 26 & 0.98 & 10 \\
\hline $\begin{array}{l}\text { Bouzgarrou } \\
2009\end{array}$ & Tunisia & $58 / 103$ & 24 & 24 & 10 & 42 & 49 & 12 & 0.69 & 10 \\
\hline $\begin{array}{l}\text { Ognjanovic } \\
2009\end{array}$ & USA & $118 / 214$ & 39 & 57 & 22 & 67 & 106 & 41 & 0.94 & 12 \\
\hline Li 2011 & China & $158 / 355$ & 132 & 25 & 1 & 278 & 72 & 5 & 0.89 & 13 \\
\hline
\end{tabular}




\section{Meta-analysis results}

As no statistically significant heterogeneity was observed in our meta-analysis, all pooled OR were derived from the fixed-effects models. Table 3 lists the main results of the meta-analysis of IL-10 -1082 G/A polymorphism and HCC risk in all of the four models (Figure 2, GG vs $\mathrm{AA}: \mathrm{OR}=0.84,95 \% \mathrm{CI}=0.57-1.25 ; \mathrm{AG}$ vs $\mathrm{AA}: \mathrm{OR}=0.85$,
95\%CI $=0.70-1.05 ; \quad$ Dominant model: $\mathrm{OR}=0.85$, 95\%CI $=0.70-1.03$; Recessive model: $\mathrm{OR}=0.92,95 \% \mathrm{CI}=$ 0.64-1.32). Sub-group analysis was next stratified by ethnicity. The meta-analysis included four studies ( 735 cases and 1572 controls) in Asian populations and two studies (176 cases and 317 controls) in mixed populations. No significant association was detected in all genetic models of stratified sub-group analysis by race.

Table 3. Summary of different comparative results.

\begin{tabular}{|c|c|c|c|c|c|c|c|c|c|c|}
\hline \multirow[t]{2}{*}{ Variables } & \multirow[t]{2}{*}{$\mathbf{N}$} & \multirow{2}{*}{$\begin{array}{l}\text { Cases/ } \\
\text { controls }\end{array}$} & \multicolumn{2}{|l|}{ GG vs AA } & \multicolumn{2}{|l|}{ AG vs AA } & \multicolumn{2}{|c|}{ Dominant model } & \multicolumn{2}{|l|}{ Recessive model } \\
\hline & & & OR(95\%CI) & $\mathrm{I}^{2}$ & OR(95\%CI) & $\mathrm{I}^{2}$ & OR(95\%CI) & $\mathrm{I}^{2}$ & OR(95\%CI) & $I^{2}$ \\
\hline Total & 6 & $911 / 1889$ & $0.84(0.57-1.25)$ & $0.0 \%$ & $0.85(0.70-1.05)$ & $0.0 \%$ & $0.85(0.70-1.03)$ & $0.0 \%$ & $0.92(0.64-1.32)$ & $0.0 \%$ \\
\hline \multicolumn{11}{|l|}{ Ethnicity } \\
\hline Asian & 4 & $735 / 1572$ & $0.65(0.36-1.17)$ & $0.0 \%$ & $0.84(0.66-1.06)$ & $0.0 \%$ & $0.82(0.65-1.03)$ & $0.0 \%$ & $0.72(0.41-1.26)$ & $0.0 \%$ \\
\hline Mixed & 2 & $176 / 317$ & $1.06(0.62-1.82)$ & $0.0 \%$ & $0.90(0.60-1.36)$ & $0.0 \%$ & $0.94(0.64-1.39)$ & $0.0 \%$ & $1.11(0.68-1.80)$ & $0.0 \%$ \\
\hline
\end{tabular}

$\mathrm{N}$ : number; $I^{2}$ : Inconsistency index; CI: confidence interval; OR: odds ratio

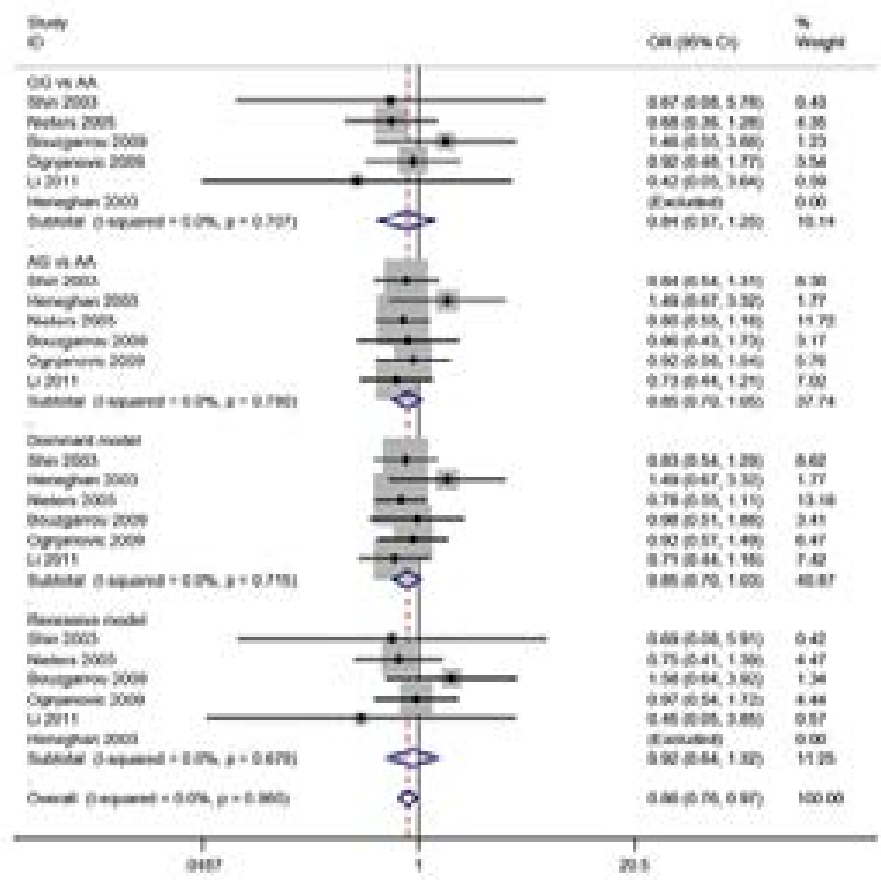

Figure 2. Forest plots of the association between IL-10 -1082 G/A polymorphism and HCC risk 


\section{Sensitivity analysis}

Sensitivity analysis was performed to assess the influence of each individual article on the pooled OR by deleting each study individually. No single article influenced the pooled ORs, suggesting stable results (Figure 3).

\section{Publication bias}

The Egger's test was performed to assess the publication bias. There was no evidence of publication bias visually from the funnel plot (Figure 4), indicating low publication bias of our meta-analysis.

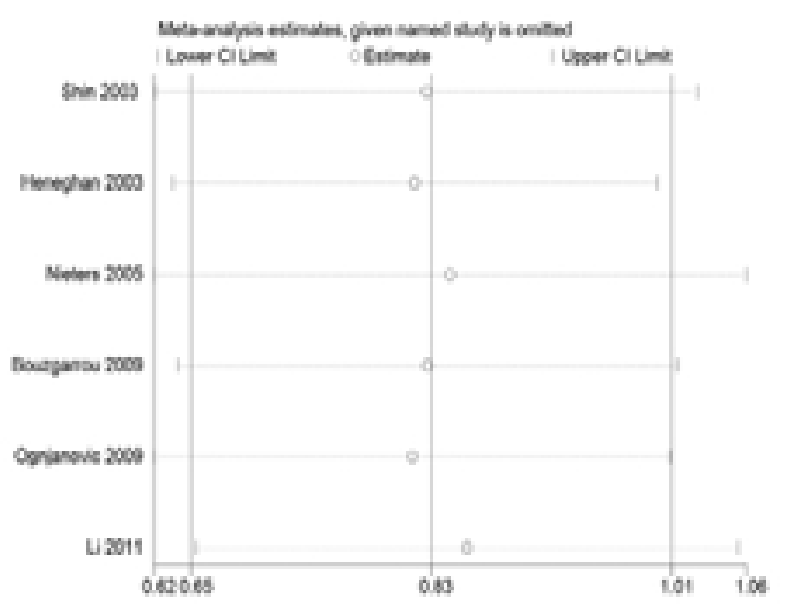

Figure 3. Sensitivity analysis of the IL-10 -1082 G/A polymorphism with HCC risk

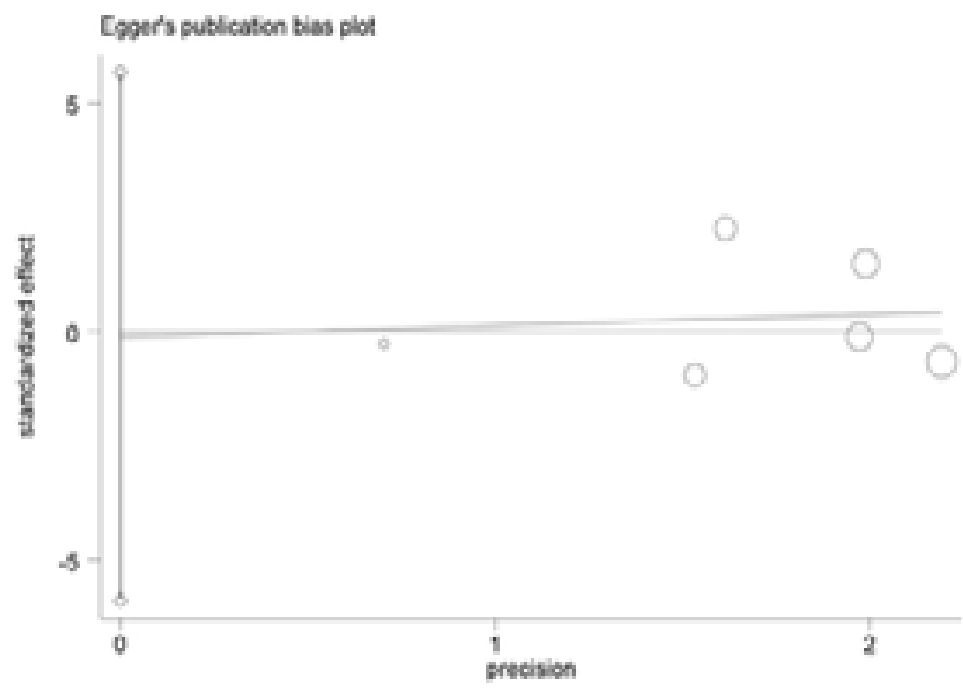

Figure 4. Egger's funnel plot test

\section{Discussion}

HCC is a common malignant tumor caused by complex interactions between environmental and genetic factors. With increased attention to genetic susceptibility to carcinogenesis, more and more studies are devoted to investigation of genetic variants and HCC risk. IL-10 plays a key role in anti-inflammation and can block tumor im- mune surveillance to inhibit T-cell immunity ${ }^{22}$. A previous study suggested that the secretion of IL-10 is determined largely $(74 \%)$ by heritable factors ${ }^{23}$. Several studies have found an association between the IL-10 -1082 G/A polymorphism and oral cancer,head and neck cancer ${ }^{24,25}$. Because meta-analysis is a suitable method to evaluate small effects in genetic association studies, we designed 
this study to systematically evaluate the association of the IL-10 -1082 G/A polymorphism with HCC risk.

This is the first meta-analysis of the relationship between the IL-10 -1082 G/A polymorphism and HCC risk. After literature search and screening, six studies were selected for analysis, with a total of 2800 subjects. Although data from individual studies suggested a relationship, the overall result of our meta-analysis argued against an association of IL-10 -1082G/A polymorphism with HCC risk in all genetic models. Ethnicity-related subgroup analyses also did not reveal a significant association between IL$10-1082 \mathrm{G} / \mathrm{A}$ and HCC risk in any of the comparisons. Green tea has been found to have anti-inflammatory, anti-oxidative and anti-carcinogenic properties ${ }^{26}$. Li et al. found that the IL-10 -1082 G/A polymorphism was associated with increased risk of cancer for non-drinkers of green tea, but decreased risk among green tea drink$\mathrm{ers}^{21}$. In addition, a previous study demonstrated that haplotypes(-1082 G/A, -819 T/C, and -592 A/C) of the IL-10 gene may synergistically increase the risk of $\mathrm{HCC}^{16}$. Only two articles have studied gene-gene and gene-environment interactions, we can not do further subgroup study. One possibility is that the IL-10 $-1082 \mathrm{G} / \mathrm{A}$ polymorphism itself may not contribute to the risk of HCC, or have only limited effect on HCC that depends on neighboring variants or environmental factor.

There are several limitations of this meta-analysis. First, we did not have the original data for included studies to adjust estimates and analyze for differences due to gender, age, drinking, smoking, lifestyle, body mass index, or other characteristics. Second, our study only included articles published in English, which might have limited the results of the meta-analysis. Third, gene-gene and gene-environment interactions have not been evaluated due to the absence of original data. Therefore, additional studies are needed to obtain more reliable results. Fourth,The statistical powers of included articles were relatively low,further well-designed and large-scale studies should be performed to further evaluate this association. Finally, the inclusion criteria for cases and controls were not clearly defined in all the included articles, which may have influenced the findings.

In summary, the results of this meta-analysis indicated that there is no association between the $-1082 \mathrm{G} / \mathrm{A}$ polymorphism of IL-10 and HCC susceptibility. Further studies estimating the effect ofgene-gene and gene-environment interactions may ultimately provide more comprehensive understanding of the association.

\section{Acknowledgement}

This study was supported by the Zhejiang Medical and Health Science and Technology Project (no.2019KY248).

\section{Conflict of interest}

None declared.

\section{References}

1. Jemal A, Bray F, Center MM, Ferlay J, Ward E and Forman D. Global cancer statistics. CA Cancer J Clin. 2011; 61: 69-90.

2. El-Serag HB.Epidemiology of viral hepatitis and hepatocellular carcinoma. Gastroenterology. 2012;142: 12641273.

3. Koh WP, Robien K, Wang R, Govindarajan S, Yuan JM, Yu MC. Smoking as an independent risk factor for hepatocellular carcinoma: the Singapore Chinese Health Study. Br J Cancer. 2011;105:1430-1435.

4. Akkiz H, Kuran S, Akgöllü E, Usküdar O, Bekar A, Bayram S. The role of interleukin 28B gene polymorphism in Turkish patients with hepatocellular carcinoma. Ann Hepatol. 2014;13:788-795.

5. Thavaraj S, Paterson IC, Hague A and Prime SS. Over-expression of TGF-beta1 in Smad4-deficient human oral carcinoma cells causes tumour regression in vivo by mechanisms that sensitize cells to apoptosis. $J$ Pathol. 2005; 205: 14-20.

6. Vairaktaris E, Yiannopoulos A, Vylliotis A, Yapijakis C, Derka S, Vassiliou S, Nkenke E, Serefoglou Z, Ragos V, Tsigris C, Vorris E, Critselis E, Avgoustidis D, Neukam FW and Patsouris E. Strong association of interleu-kin-6-174 G>C promoter polymorphism with increased risk of oral cancer. Int J Biol Markers. 2006; 21: 246-250.

7. Vairaktaris E, Yapijakis C, Serefoglou Z, Derka S, Vassiliou S, Nkenke E, Vylliotis A, Wiltfang J, Avgoustidis D, Critselis E, Neukam FW and Patsouris E. The interleukin-8 (-251A/T) poly-morphism is associated with increased risk for oral squamous cell carcinoma. Eur J Surg Oncol. 2007; 33: 504-507.

8. Hsu HJ, Yang YH, Shieh TY, Chen CH, Kao YH, Yang $\mathrm{CF}$ and Ko EC. TGF-beta1 and IL-10 single nucleotide polymorphisms as risk factors for oral cancer in Taiwanese. Kaohsiung J Med Sci. 2015; 31: 123-129. 
9. Barry JC, Shakibakho S, Durrer C, Simtchouk S, Jawanda KK, Cheung ST, Mui AL, Little JP. Hyporesponsiveness to the anti-inflammatory action of interleukin-10 in type 2 diabetes. Sci Rep. 2016;6:21244.

10. Tanikawa T, Wilke CM, Kryczek I, Chen GY, Kao J, Núñez G, Zou W. Interleukin-10 ablation promotes tumor development, growth, and metastasis. Cancer Res. 2012;72, 420-429.

11. Acuner-Ozbabacan ES, Engin BH, Guven-Maiorov E, Kuzu G, Muratcioglu S, Baspinar A, Chen Z, Van Waes C, Gursoy A, Keskin O, Nussinov R. The structural network of Interleukin-10 and its implications in inflammation and cancer. BMC Genomics. 2014;15:S2.

12. Mörmann M, Rieth H, Hua TD, Assohou C, Roupelieva M, Hu SL, Kremsner PG, Luty AJ, Kube D.Mosaics of gene variations in the interleukin-10 gene promoter affect interleukin-10 production depending on the stimulation used. Genes Immun. 2004;5:246-255.

13. Turner DM, Williams DM, Sankaran D, Lazarus M, Sinnott PJ and Hutchinson IV. An investigation of polymorphism in the interleukin-10 gene promoter. Eur J Immunogenet. 1997; 24: 1-8.

14. Camargo MC, Mera R, Correa P, Peek RM Jr, Fontham ET, Goodman KJ, Piazuelo MB, Sicinschi L, Zabaleta J, Schneider BG.Interleukin-1beta and interleukin-1 receptor antagonist gene polymorphisms and gastric cancer: a meta-analysis. Cancer Epidemiol Biomarkers Prev. 2006;15:1674-1687.

15. Tobias A. Assessing the influence of a single study in the meta-analysis estimate. Stata Tech Bull. 1999;8:15-17. 16. Shin HD, Park BL, Kim LH, Jung JH, Kim JY, Yoon JH, Kim YJ, Lee HS.Interleukin 10 haplotype associated with increased risk of hepatocellular carcinoma. Hum Mol Genet. 2003; 12:901-906.

17. Heneghan MA, Johnson PJ, Clare M, Ho S, Harrison PM, Donaldson PT. Frequency and nature of cytokine gene polymorphisms in hepatocellular carcinoma in Hong Kong Chinese. Int J Gastrointest Cancer. 2003; 34:1926.
18. Nieters A, Yuan JM, Sun CL, Zhang ZQ, Stoehlmacher J, Govindarajan S, Yu MC.Effect of cytokine genotypes on the hepatitis B virus-hepatocellular carcinoma association. Cancer. 205; 103:740-748.

19. Bouzgarrou N, Hassen E, Farhat K, Bahri O, Gabbouj S, Maamouri N, Ben Mami N, Saffar H, Trabelsi A, Triki $\mathrm{H}$, Chouchane L.Combined analysis of interferon-gamma and interleukin-10 gene polymorphisms and chronic hepatitis C severity. Hum Immunol. 2009; 70:230-236.

20. Ognjanovic S, Yuan JM, Chaptman AK, Fan Y, Yu MC. Genetic polymorphisms in the cytokine genes and risk of hepatocellular carcinoma in low-risk non-Asians of USA. Carcinogenesis. 2009; 30:758-762.

21. Li Y, Chang SC, Goldstein BY, Scheider WL, Cai L, You NC, Tarleton HP, Ding B, Zhao J, Wu M, Jiang Q, Yu S, Rao J, Lu QY, Zhang ZF, Mu L. Green tea consumption, inflammation and the risk of primary hepatocellular carcinoma in a Chinese population. Cancer Epidemiol. 2011;35:362-368.

22. Brooks DG, Trifilo MJ, Edelmann KH, Teyton L, McGavern DB, Oldstone MB. Interleukin-10 determines viral clearance or persistence in vivo. Nat Med. 2006;12:1301-1309.

23. Westendorp RG, Langermans JA, Huizinga TW, Verweij CL, Sturk A.Genetic influence on cytokine production in meningococcal disease. Lancet. 1997; 349: 1912 1913.

24. Chen H, Tang J, Shen N, Ren K.Interleukin 10 gene rs1800896 polymorphism is associated with the risk of prostate cancer. Oncotarget. 2017;866204-66214.

25. Huang W, Song J, Jia XW, Chen YX, Shi J, Jiang X.Interleukin-10 rs1800896 polymorphism is associated with increased head and neck cancer risk but not associated with its clinical stages. Oncotarget. 2017;8:37217-37224.

26. Tipoe GL, Leung TM, Hung MW, Fung ML. Green tea polyphenols as an antioxidant and anti-inflammatory agent for cardiovascular protection. Cardiovasc Hematol Disord Drug Targets. 2007;7:135-144. 